\title{
Investigation of the Effect of Rubber Based Offset Ink printed on packaging Cardboard on the Strength Properties of Packing Cartons
}

\author{
Dogan Tutak \\ Department of Printing Technologies \\ School of Applied Science \\ Marmara University, Istanbul - Turkey \\ Bekir Keskin \\ Department of Printing technologies \\ Gazi University, Ankara - Turkey \\ Department of Chemical and Paper Engineering \\ College of Engineering and Applied Sciences \\ Western Michigan University \\ Kalamazoo, Michigan - USA \\ Said Abubakr \\ Paul D. Fleming III \\ Department of Chemical and Paper Engineering \\ College of Engineering and Applied Sciences \\ Western Michigan University, Kalamazoo, Michigan - USA
}

\begin{abstract}
Paperboards show different behaviors due to their structures. For example, if the paperboard thickness increases its strength increases. Different applications can affect paperboard structure especially coatings and inks. Because of this reason, in this study, the effect of offset printing ink on cardboard strength was investigated. In order to control the ink coated paperboard strength properties after printing, different types of paperboards were used with different grammage, thickness and surface properties. Paperboard samples were 1-ply, 2-ply, 3-ply and 5 different grammages as 215, 240, 250, 290 and $350 \mathrm{~g} / \mathrm{m}^{2}$.All samples were printed with a one-unit offset printing machine. After drying, tensile, elongation, stiffness, tear and bursting tests were performed on the both printed and unprinted paperboards according to TAPPI standards. The paperboards showed different behaviors according to the applied tests. Some of them show significant changes, but some of them do not. The printed and unprinted sample values were compared only for the same paperboard grades.
\end{abstract}

Keywords: Paperboard, ink, paperboard strength, paper tests

\section{Introduction}

Paperboards are environmentally-friendly single or multi-ply (fig 1.) materials widely used for packaging applications.[1,2].

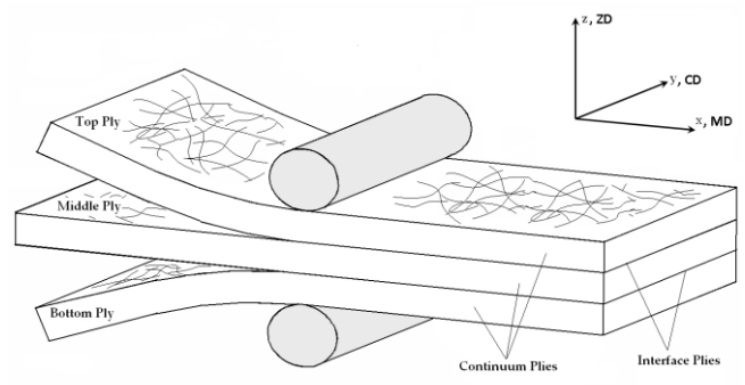

Figure 1.3-ply Paperboard structure illustration [3]. 
The use of cellulosic based paper or paperboard products in the paper-based packaging industry is quite common, due to their properties such as stability, optical properties, printable surfaces, impressive shelf display, etc. In addition, they are easily recyclable and biodegradable in nature.[4].

It is possible to produce many products with paper or paperboard; books, magazines, newspapers, visual products, packaging products, shipping boxes and personal care products. In particular, the reason for the use of paperboard in packaging production is that the product is easily shaped economically [5].Also, paperboard is a very good material to promote the product. contains goods as a package with visual and aesthetic prints. In addition, the rise in online sales has led to an increase in the amount of paperboard packaging used to carry and store these products. In addition, online sale has shifted part of the responsibility of recycling from retailers to consumers.

Coated and stabilized paperboards for printing are used as common substrates in the packaging and printing industries. Regardless of the printing technique, coatings provide excellent print quality. In addition, coatings show stable support on the surface of the paperboard, allowing minimal surface damage and folding [6].

There are many additive and coating materials in and on the paperboard. Fillers may also improve surface properties of paper, which may also have a positive effect on the printability of the final product. The use of fillers however brings additional challenges in papermaking. Fillers have poor binding capacity, which limits their use. Poor binding results in lower strengths in paper [1]. Without more information about filler additions and the nature of the board machine, it is impossible to determine how fillers affect paperboard strength properties.

The ink that is printed on the paperboards acts just like the related coatings of the paperboard and it affects mostly surface properties and the near surface paperboard bonded structure properties. Sometimes the ink layer strengthens the surface structure, sometimes on the contrary, it damages the internal structure of the paperboard and bond properties [7].Figures 2 and 3 illustrate respectively the application of ink on a surface and cross section of a paperboard.

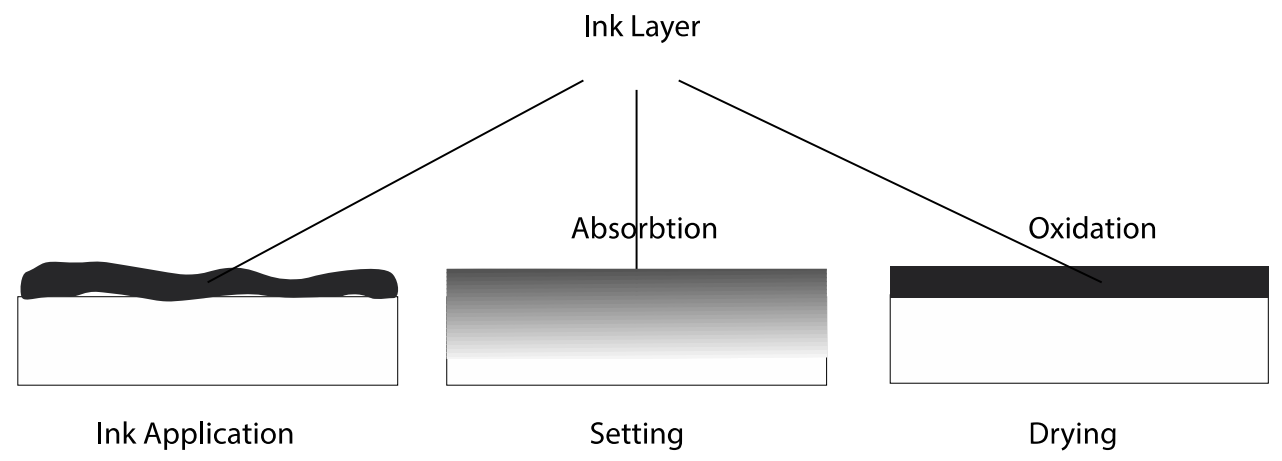

Figure 2.Setting of ink on the surface as a coating.

Offset inks dry by absorption and/or oxidation [8]. The Vanson-VS314rubber-based ink used here driestotally by absorption.

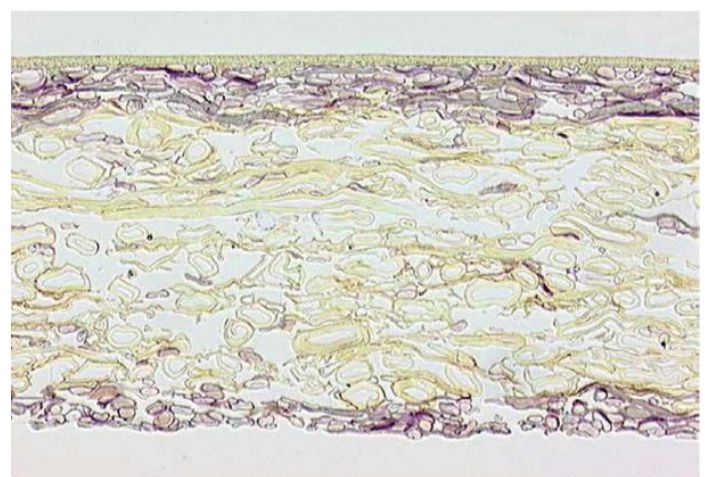

Figure 3.Cross section of paperboard [9].

The environment where the paperboard and paperboard packages are stored and exhibited after printing are also very important. Particularly, external factors, such as humidity and temperature in storage, can directly affect the durability of the printed paperboard [10]. 


\section{Experimental part}

In this study, in order to control the ink coated paperboard strength properties after printing, different type paperboards were used with different grammage, thickness and surface properties. Paperboard grammages; 215, 240, 250, 290 and $350 \mathrm{~g} / \mathrm{m}^{2}$, (Paperboards A and C were 1-ply, B and D were 2-ply, and E was 3-ply) were examined. All samples were printed with a one-unit ABDICK offset printing machine. Vanson-VS314 rubber- based ink (Bordeaux Red) was used for printing because rubber-based ink can be left in the ink pan for extended periods of time without forming a skin [8]. The coated side of each sample was printed and covered by a $10 \times 15 \mathrm{~cm}$ rectangle by this ink as a solid tone (100\%) for seeing maximum ink effects to the paperboards.

The tensile properties and elongation of the paperboard and ink covered paperboards were tested by using an Instron tensile tester. Tensile strength and elongation were measured in accordance with TAPPI T 494 om- 01 "Tensile testing of paper." The tearing strength of the paperboard and ink covered paperboard were tested by using a TMI tearing tester according to TAPPI test method T 414 om-12 "Internal tearing resistance of paper." The bending-stiffness resistance of the paperboard and ink covered paperboard was tested by using a Gurley Bending Resistance tester according to TAPPI T 489om-15 "Bending resistance (stiffness) of paper and paperboard." The bursting properties of the paperboards and ink covered paperboards were tested by using a Mullen tester according to TAPPI T 403-om-15 "Bursting strength of paper." All tests were applied on both printed and unprinted paperboards after conditioning for 24 hours at TAPPI conditions $23 \pm 1{ }^{\circ} \mathrm{C}$ and $50 \pm 2 \%$ of RHina conditioning room.

The properties of the different paperboards are summarized in Table 1. Following that table are listed additional details about the paperboards.

Table 1.The properties of paperboards

\begin{tabular}{ccccccccccc}
\cline { 1 - 1 } $\begin{array}{c}\text { Cardboard } \\
\text { Types }\end{array}$ & $\begin{array}{c}\text { Basis } \\
\text { Weight } \\
\left(\mathrm{g} / \mathrm{m}^{2}\right)\end{array}$ & $\begin{array}{c}\text { Thickness } \\
(\mu \mathrm{m})\end{array}$ & $\begin{array}{c}\text { Roughness } \\
\text { SU }\end{array}$ & $\begin{array}{c}\text { PPS } \\
\text { Porosity } \\
\text { ml/min }\end{array}$ & $\begin{array}{c}\text { Gloss } \\
75^{\circ}\end{array}$ & Brightness & $\mathrm{L}^{*}$ & $\mathrm{a}^{*}$ & $\mathrm{~b}^{*}$ \\
$\mathbf{A}$ & 250 & 9.8 & 16.1 & 12164 & 60.2 & 89.9 & 92.9 & 2.58 & - \\
$\mathbf{B}$ & 240 & 18.5 & 71.8 & 5767 & 53.3 & 83.2 & 94.4 & 0.49 & 2.57 \\
$\mathbf{C}$ & 215 & 11 & 140.4 & 16.3 & 8.0 & 93.3 & 94.5 & 2.15 & - \\
$\mathbf{D}$ & 290 & 14.4 & 186.9 & 3342 & 40.1 & 78.6 & 90.1 & 0.65 & 0.15 \\
$\mathbf{E}$ & 350 & 16.7 & 144.1 & 6418 & 41.1 & 80.1 & 91.1 & 0.57 & 0.34 \\
\hline \hline
\end{tabular}

Specifications of Paperboard Types

A- $250 \mathrm{~g} / \mathrm{m}^{2}$,one ply, two sides glossy coated paperboard. Both sides the same.

B- $240 \mathrm{~g} / \mathrm{m}^{2}$ two side coated 2-ply paperboard, but front side better calendared thanback side.

C- $215 \mathrm{~g} / \mathrm{m}^{2}$ high grade two sides same uncoated paperboard, it is just 1-ply.

D- $290 \mathrm{~g} / \mathrm{m}^{2}$ it is a 2-ply, front side coated paperboard, its back side is gray no coating on back side.

E- $350 \mathrm{~g} / \mathrm{m}^{2}$ it is a 3-ply,both side coated paperboard, front side coated two times.

Photographs of both sides of the paperboards are shown in Figure 4.

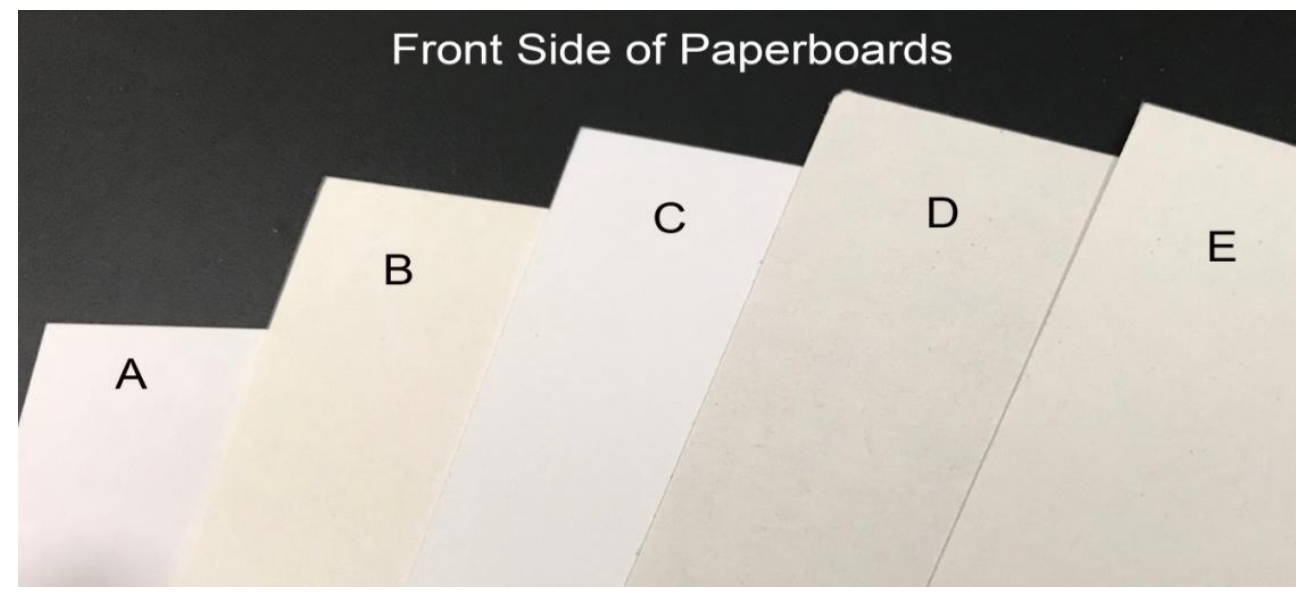




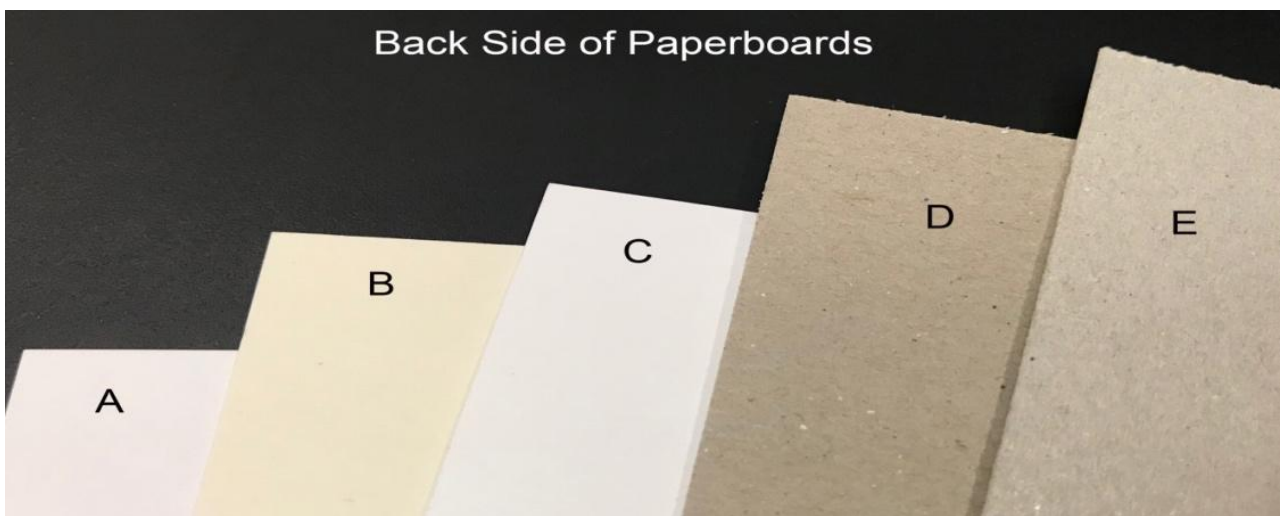

Figure 4.Two sides of paperboards

Permeability Coefficient, $\mathrm{K}\left(\mu \mathrm{m}^{2}\right)$ value calculations were made according to the Pal equation [11],shown as Equation 1, using results from the Parker Print Surf (PPS) Porosity tester.

$$
\text { Permeability Coefficient, } \mathrm{K}\left(\mu \mathrm{m}^{2}\right)=0.048838^{*} \mathrm{Q}(\mathrm{ml} / \mathrm{min}) * \mathrm{~L}(\mathrm{~m})
$$

(1)

Table 2.Air Permeability Coefficient of Paperboards

\begin{tabular}{|c|c|c|c|c|c|}
\hline \multirow{2}{*}{ Paperboard } & \multicolumn{2}{|c|}{$\begin{array}{c}\text { Avg. } \\
\text { Thickness } \\
(\mu \mathrm{m})\end{array}$} & \multicolumn{2}{|c|}{ PPS Porosity } & \multicolumn{2}{c|}{$\begin{array}{c}\text { Permeability Coefficient } \\
\left(\mu \mathrm{m}^{2}\right)\end{array}$} \\
\cline { 3 - 6 } & & Avg. & Std. & Avg. & Std. \\
\hline A & 9.8 & 12164 & 854 & 0.005 & 0.00041 \\
\hline B & 18.5 & 5767 & 245 & 0.005 & 0.00022 \\
\hline C & 11 & 16.3 & 0.4 & 0.000008 & 0.00000021 \\
\hline D & 14.4 & 3342 & 62 & 0.002 & 0.000043 \\
\hline E & 16.7 & 6418 & 427 & 0.005 & 0.00035 \\
\hline
\end{tabular}

Table 2 summarizes the results of PPS Porosity measurements along with the calculated air permeability of the different paperboards. The air permeability is of units of area and it is proportional to an effective capillary area crosssection of the paperboards. This is a measure of how fast a fluid (gas or liquid) can be transported through the given paperboard [11].

\section{Results and Discussions}

The results of tensile, elongation, bending-stiffness, tear and bursting tests were obtained for printed and unprinted paperboards that have five different physical and surface properties. Test results obtained from paperboards were not only measured machine direction (MD) but also in the cross direction (CD). The results were converted to graphics in addition to tables. Because of their different physical properties, paperboards were not compared with one another, they were only compared as printed and unprinted samples for each type of paperboard. Graphs and their explanations are presented in Figures 5-9. Each test was repeated at least five times and averages and standard deviations were calculated.

Table 3.Density and Ink Thickness values of printed paperboards

\begin{tabular}{|l|c|c|c|c|c|}
\hline Paper Type & A & B & C & D & E \\
\hline Density & 2.20 & 2.01 & 1.30 & 2.21 & 2.05 \\
\hline STDEV & 0.01 & 0.03 & 0.02 & 0.03 & 0.05 \\
\hline Ink Thickness $(\mu \mathrm{m})$ & 5.20 & 5.60 & 4.00 & 5.40 & 5.40 \\
\hline STDEV & 0.08 & 0.16 & 0.18 & 0.21 & 0.11 \\
\hline
\end{tabular}


Table 3 summarizes the optical densities and ink film thickness of the Vanson-VS314 rubber-based ink printed on the paperboards. Except for sample C, the optical ink densities are very high, indicating good ink transfer. Usually ink density is a measure of ink film thickness. Thus, sample $\mathrm{C}$ has both the thinnest ink film and the lowest density.

The results of Tensile tests are given in Figure 5.
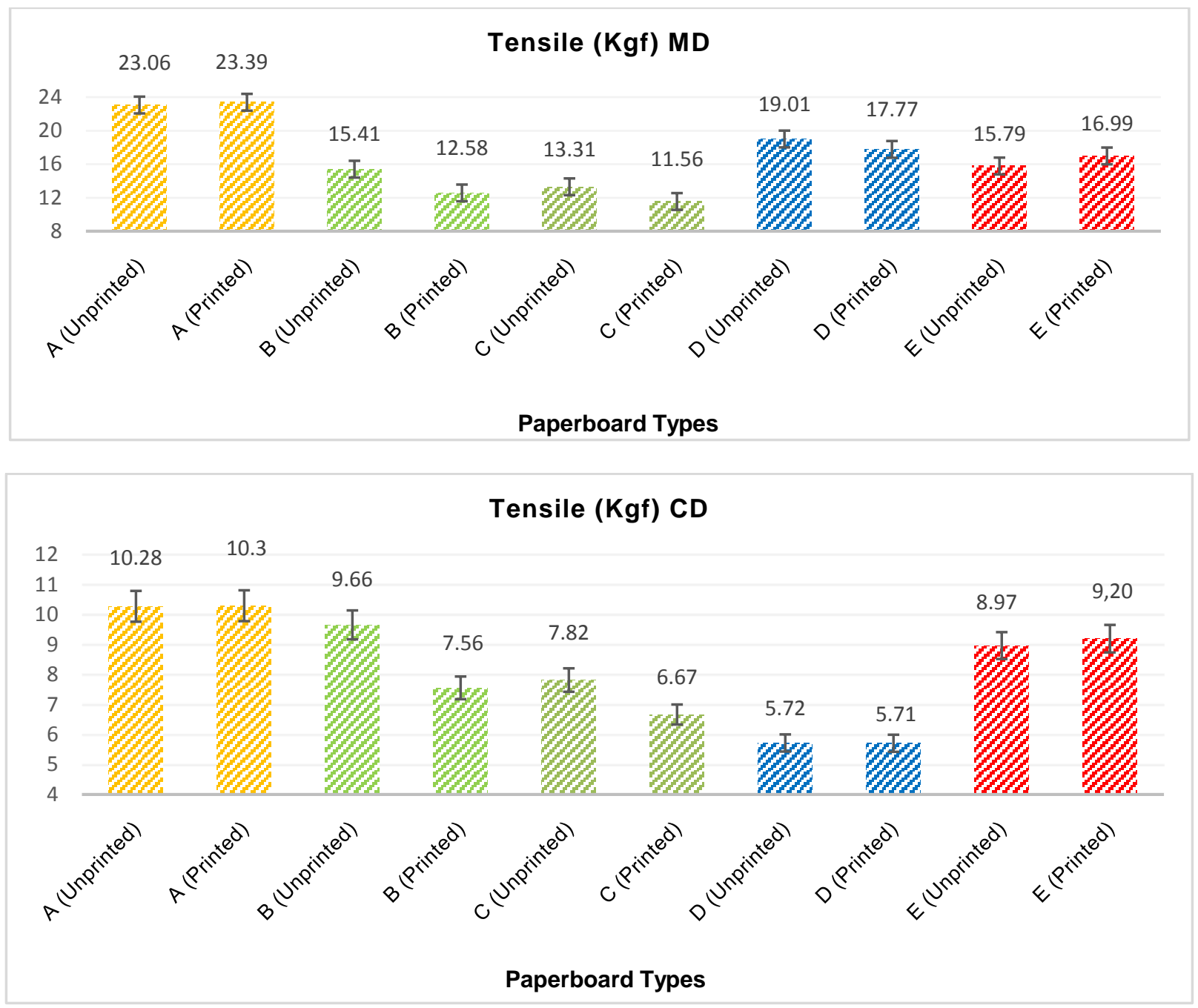

Figure 5. Tensile test results

Figure 5. shows tensile properties of paperboards. Itis observed that the tensile strengths of the printed surfaces decreased in both MD and CD, except for samples A,D and E,but these increases were insignificant. The changes for 2ply B were $18 \%$ decrease MD and $22 \%$ decrease $C D$, while for single ply, $C$ they were $13 \%$ decrease MD and $15 \%$ decrease $\mathrm{CD}$. These were the only significant changes. In is not clear why samples B and C were the only ones to show significant loss in strength. Sample B has a relatively thick ink film, while sample C has a thin ink film. Sample B has a high air permeability, while sample $\mathrm{C}$ has a low air permeability. None of these explain the observations on tensile strength. 


\section{The results of Elongation are shown in Figure 6.}

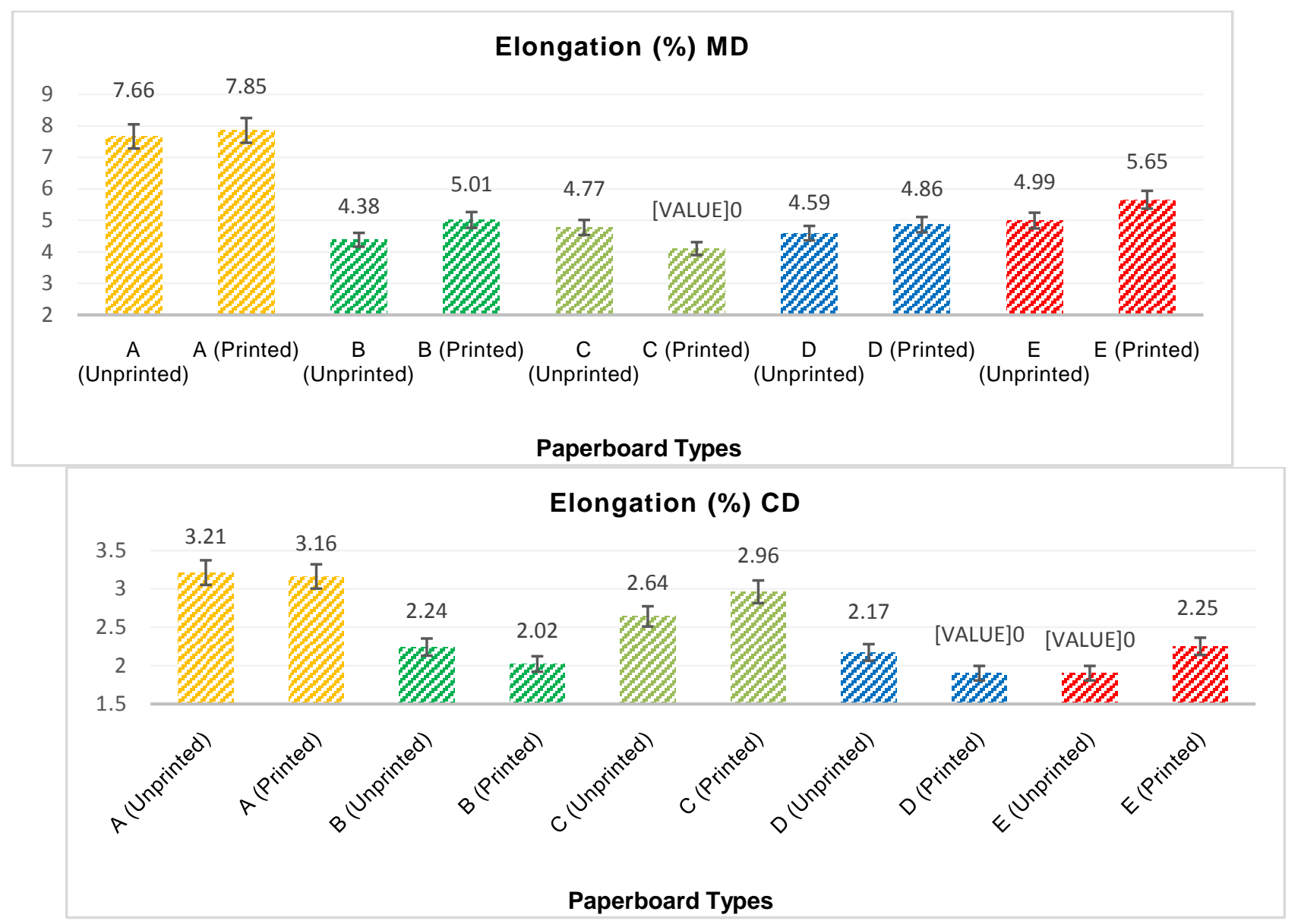

Figure 6. Elongation test results

Figure 6. illustrates elongation properties of paperboards. It can be clearly seen in the elongation results thatfor all paperboard elongation increased in the MD except for the single ply $\mathrm{C}$ paperboard. The value of Cpaperboard elongation value significantly decreased by $14 \%$, while all other values increased, although only for 2-ply B and 3-ply E are they significant. On the contrary, for CD, the 2-ply Dpaperboard significantly decreased by $12.5 \%$ and 2-ply B significantly decreased by $10 \%$. Of the increases, only 2-ply B, and 3-ply E, MD and single-ply C and 3-ply E, CD are significant. This shows that the elongation values after printing are dependent on the structure of the board, although it is hard to identify what factors control the elongation increase or decrease.

The results of Bending-Stiffness testsfor the different paperboards are shown in Figure 7.

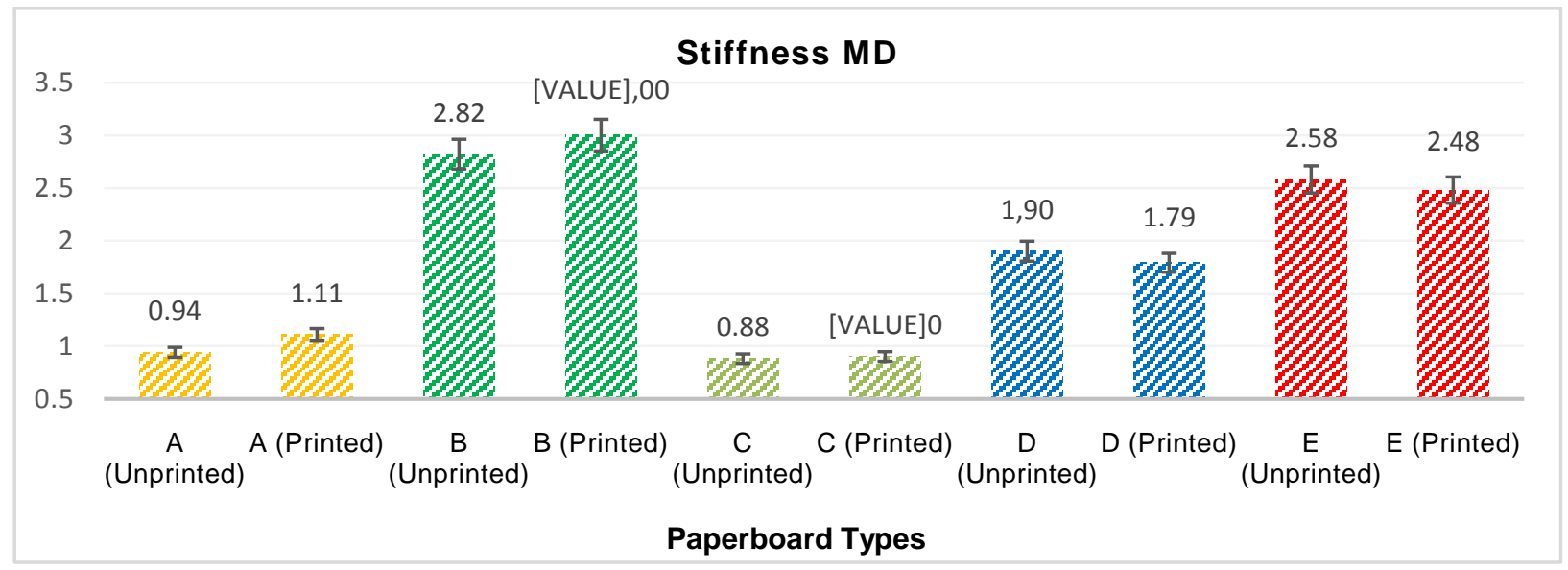




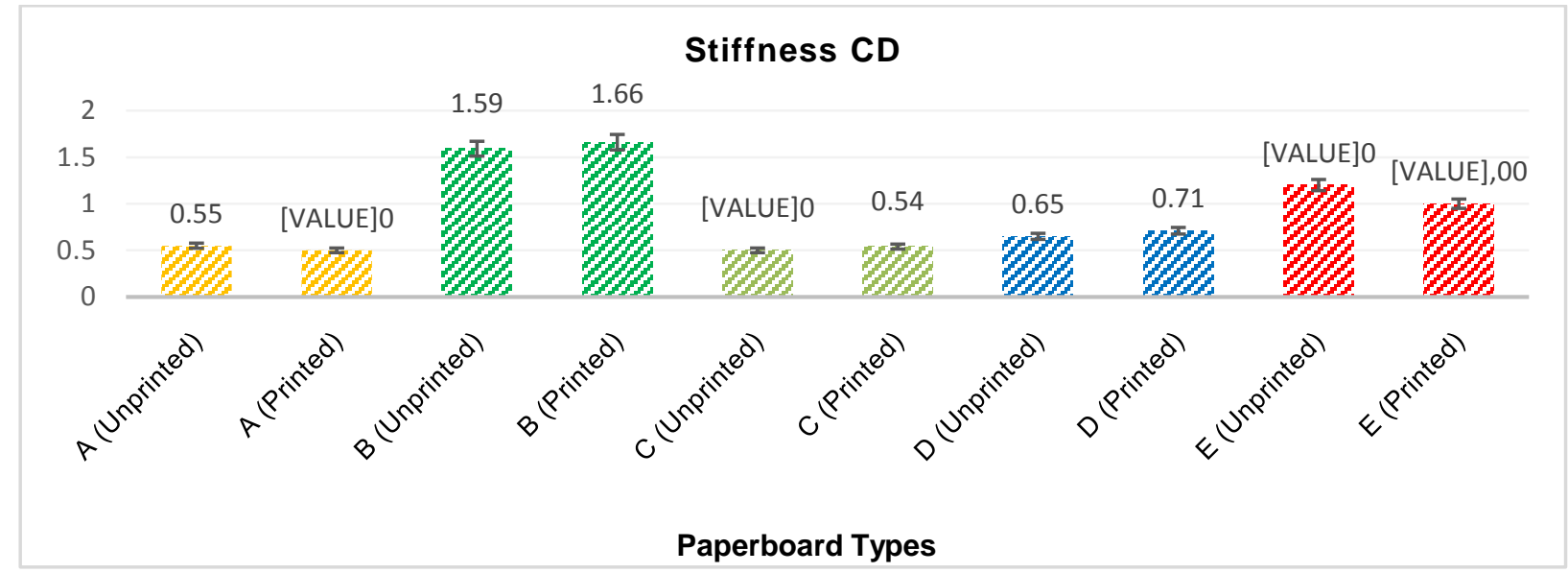

Figure 7. Stiffness test results

Figure 7. shows bending-stiffness properties of the paperboards. It is observed that the bending-stiffness values for the 3-ply Epaperboard showed a 17\%decrease in the CD, while all the other paperboard values showed negligible changes. For the MDpaperboards, all stiffness values showed negligible changes.

The results of Tearing tests are shown in Figure 8.

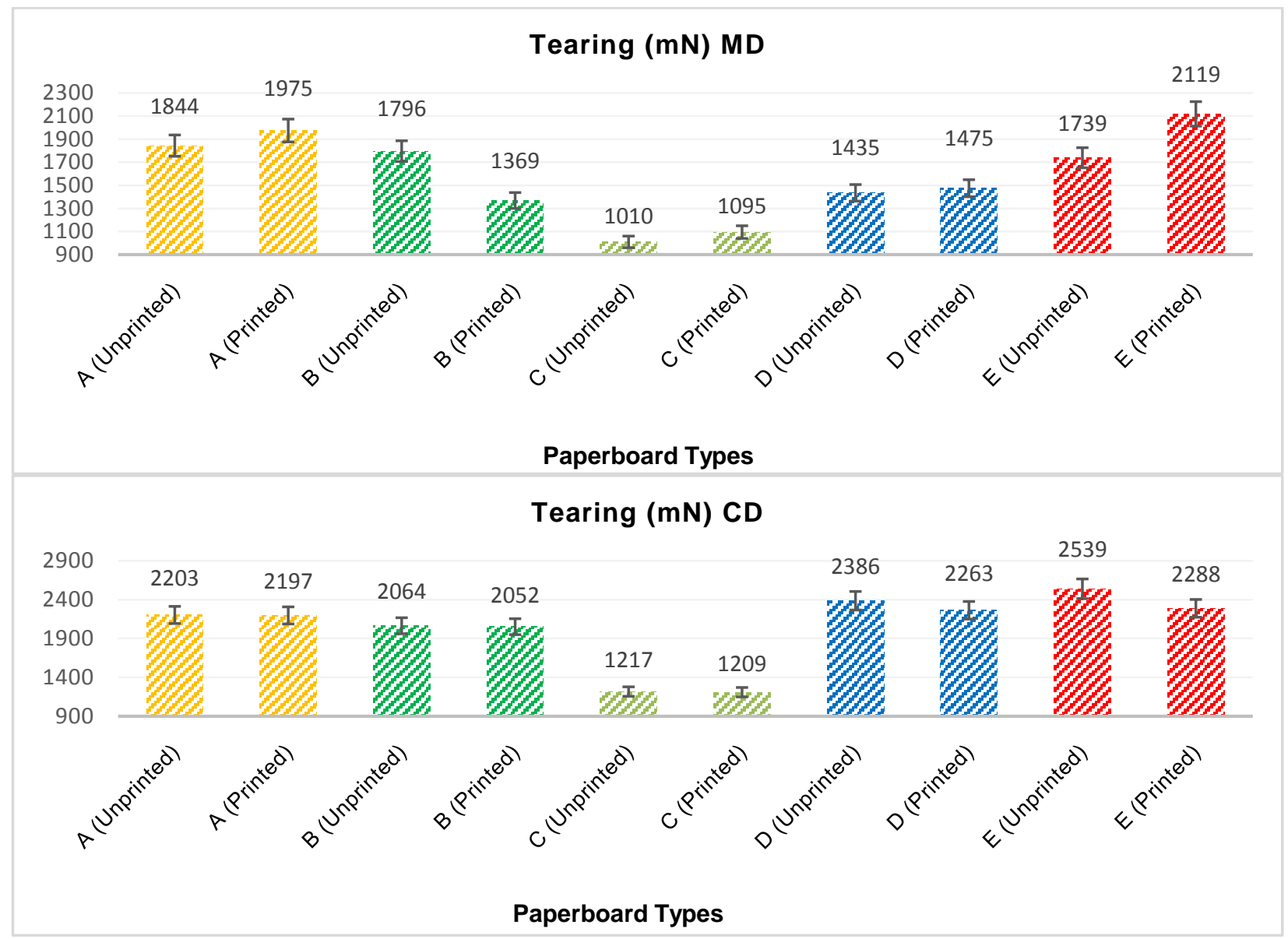

Figure 8. Tear test results

Figure 8. shows that paperboards $\mathrm{A}, \mathrm{C}$, and $\mathrm{D}$ tearing values were generally unchanged in the MD,but there was a significant decrease in 2-ply B of $24 \%$ and an increase in E of $22 \%$. However, in the CD all values decreased but, only 3 -ply paperboard 3 ply E (10\%) significantly decreased. 


\section{The results of Bursting tests are shown in Figure 9.}

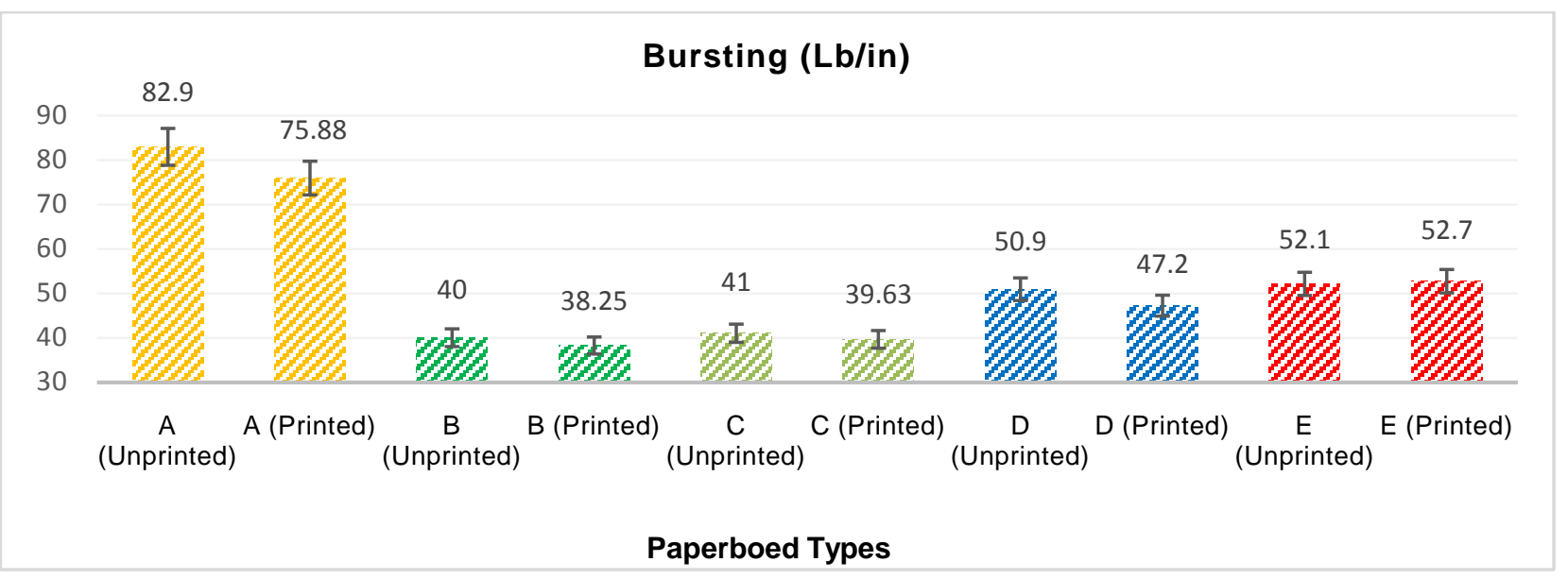

Figure 9. Bursting test results

Figure 9. illustrates bursting results for boards. It was found that the bursting values decreased for all paperboards except for $\mathrm{E}$, but none are significant.

\section{Conclusion}

The ink printed layer (it can be treated asa "coated" first layer) negatively affects mechanical properties for some multiply paperboards. These results from second and possibly third layers when printing multi-ply paperboard with offset printing the dampening solution penetrates and the layers separate (delaminate). This makes the paperboards weaker. This behavior is mostly prevalent in samples B, D and E.These samples have relatively high permeability and therefore allow water to penetrate through layers.

When looking at the one-ply, two sides glossy coated paperboard (paperboard A); the ink has little effect on strength properties. Because sample A has the highest permeability, any favorable strength effects are countered by water penetration and associated weakening of fiber-bonds. Thus, Paperboard A should have the most ink and water penetration.

One-ply two sides uncoated paperboard (paperboard C) showed significant decreases in Tensile and Elongation MD. It showed significant increase of Elongation $\mathrm{CD}$, with all other changes being negligible. Paperboard $\mathrm{C}$ has the lowest permeability, unlike Paperboard A but it shows significant changes.

The reason for this problem during the printing process for more permeable samples, is the paper surface is getting wetted and fibers absorb humidity to the inside and fibers swell and away from each other, because of the fountain solution and because the ABDICK press uses an indirect dampening system (ink and water on the same form roller) [12]. When paperboards dry they never return to initial conditions. This can be seen when comparing MD and CD direction values. These results might be different if they were printed with a waterless offset ink [12].

Still, not all effects of printed layers on paperboard properties can be explained by results here. More knowledge of the coating formulations and the manufactured paperboard parameters would be necessary. Even if all manufacturers were known, they would not reveal this information. It would take a detailed study of paperboard furnish, fillers and coating formulations for this, perhaps on the new 2 ply paperboard machine at the WMU pilot plant [13]. Printing with both rubber base and conventional offset inks would also be necessary.

\section{References}

Alén, R., Papermaking Chemistry, Finnish Paper Engineers' Association, (2007).

Dias,V.M. Kuznetsova, A., Tedim, J., et alWorld J. Nano Sci. Eng., 5:126 (2015).

Huang, H. and Nygårds, M., Nordic Pulp Paper Res. J., 25(4):505(2010).

Li, H., Yang, J., Li, P., et al., Carbohydrate Poly., 160:9(2017).

Fellersa C., Ref. Mod. in Materials Sci. and Materials Eng., Paper: Strength and Stiffness, 2001, pp 6720.

Pál, M., Novaković, D., Dedijer, S., et al., Measurement 100:99(2017).

Kirwan, M.J., "Handbook of Paper and Paperboard Packaging Technology”,2. edition, John Wiley \& Sons, 2013. 
Robert Leach, The Printing Ink Manual, Springer Science \& Business Media, Dec 6, 2012, Chapter 6.https://www.iggesund.com/en/knowledge/knowledge-publications/paperboard-the-iggesund-way/thepaperboard-product/[1Sept2018].

Uchino, T., Tanaka, F., Hamanaka, D., et al.,International Symposium Postharvest Pacifica 2009, Napier, New Zealand,2010, 880(64):533.

Lokendra Pal, Margaret K. Joyce and P. D. Fleming, "A Simple Method for Calculation of Permeability Coefficient of Porous Media”, TAPPI J., September 2006, p 10.

Helmut Kipphan, Handbook of Print Media Technologies and Production Methods Springer-Verlag Berlin Heidelberg New York, 2001, p221.

Big changes unfold at WMU Pilot Plant,http://wmupilotplant.com/wmu-paper-pilot-plant-relocation 